\title{
Externalities and Regulation in Card Payment Systems
}

\author{
JEAN-CHARLES ROCHET * \\ IDEI, Toulouse University \\ JEAN TIROLE \\ IDEI, Toulouse University, and MIT
}

\begin{abstract}
The paper offers a roadmap to the current economic thinking concerning interchange fees. After describing the fundamental externalities inherent in payment systems and analysing merchant resistance to interchange fee increases and the associations' determination of this fee, it derives the externalities' implications for welfare analysis. It then discusses whether consumer surplus or social welfare is the proper benchmark for regulatory purposes. Finally, it offers a critique of the current regulatory approach, and concludes with a call for more novel and innovative thinking about how to reconcile regulators' concerns and the industry legitimate desire to perform its balancing act.
\end{abstract}

\section{Introduction}

Multi-party card payment systems such as Visa and MasterCard set interchange fees, which are transaction-based payments from the merchant's bank, the acquirer, to the cardholder's bank, the issuer. The magnitude and sometimes even the very legitimacy of these interchange fees have been repeatedly questioned either directly (the focus of this paper), or indirectly in cases involving tying between debit and credit ${ }^{1}$, the no-surcharge rule $^{2}$, system duality ${ }^{3}$, and the collective determination of its level. These challenges have occurred both in courts of law (as for example the Wal-Mart case and the ongoing class action suits in the U.S.) or through regulatory decisions to constrain interchange fees (as for example by the European Commission, the UK Office of Fair Trading, and the Reserve Bank of Australia).

\footnotetext{
* Contact author. IDEI and GREMAQ (UMR 5604 CNRS), Toulouse University, France. E-mail: rochet@,cict.fr. We are grateful to Dennis Carlton, Howard Chang and Joe Farrell for useful comments. ${ }^{1}$ See the Wal-Mart case in the U.S.

${ }^{2}$ The no-surcharge rule takes various forms depending on the country. In its strictest form, it prohibits merchants from differentiating prices for card and cash payments.

${ }^{3}$ Board duality refers to the governance of one system by members that are also issuers or acquirers on another system.
} 
This paper is a progress report on what we know and don't know about the economics of card payment systems. Unfortunately, the arguments of the card payment systems and of their critics cannot, for a couple of reasons ${ }^{4}$, be assessed in the light of received competition policy doctrine.

The first specificity of the situation is that dominant systems such as Visa and, until its recent IPO, MasterCard, are not-for-profit associations. An association over the long-term operates as a cost pass-through; indeed the interchange fee is not withheld by the system but flows from the acquirer to the issuer. ${ }^{5}$ The upshot is that even a dominant card payment association cannot charge a markup above cost; that is it cannot raise the price level, where the price level is defined as the total of cardholder and merchant fees. ${ }^{6}$ Accordingly, the current regulatory debate rather reflects a concern that a high interchange fee, by reducing issuers' marginal cost and thereby the cardholders' fee, could induce too many card payments, not too few. ${ }^{7}$ Put differently, the interchange fee debate is about the systems' price structure, not level.

The second specificity is more fundamental and applies also to proprietary systems such as American Express or Diners Club, whose "interchange fee" is implicit and measured by the merchant discount: Payment systems are inherently two-sided markets, namely markets in which platforms must court two sides who want to interact with each other, and in which the price structure, that is the allocation of charges between the two sides of the market, matters. ${ }^{8}$ Two-sided platforms can be found in many industries, including software, videogames, exchanges, media and telecoms. ${ }^{9}$ It is now wellunderstood that the implementation of competition policy must be amended in order to reflect two-sidedness. ${ }^{10}$ For example, two-sided platforms often skew their price structure by charging a low (perhaps zero) price to one side of the market and a high price on the other. On such grounds, a (dominant) platform could be found guilty of predatory pricing on one side of the market and (conceivably in the European Union) of excessive pricing on the other side. Yet, this price skewness is widespread and not confined to dominant platforms. A free newspaper entrant (such as Metro) does not prey on the incumbents on

\footnotetext{
${ }^{4}$ There are other specificities, such as the need for a centralized setting of interchange fees, that won't be developed in this paper.

${ }^{5}$ Systems cover their fixed and proportional costs through the so-called "system fee".

${ }^{6}$ To be more precise, a not-for-profit system cannot just raise price, increase profit and pay dividends to its owners in the standard way. But it can affect the total price in other ways: increase its cost by producing inefficiently, increase or decrease the interchange fee to benefit the side (issuers or acquirers) with the lowest pass-through if pass-through of changes in interchange is asymmetric (as noted by Farrell 2006), steering volume away from more efficient (lower total price) competing systems, etc.

${ }^{7}$ Relatedly, there could be a concern about an over-use of high-cost payment systems, and under-use of lower-cost ones.

${ }^{8}$ There is some debate as to the exact definition of a two-sided platform. In the context of platforms like payment card networks, that essentially charge linear prices on each side of the market, two-sidedness can be defined as the non-neutrality of the allocation of the total price between the two sides (Rochet and Tirole 2005). For example a value-added tax is neutral (it does not matter whether the buyer or the seller pays it) while the interchange fee in general is not (unless merchants costlessly and perfectly pass the merchant discount through to the card users). Non-neutrality almost systematically holds in markets in which end-users incur large fixed costs or pay large fixed fees to the platform, as these cannot be passed through to the other side of the market.

${ }^{9}$ See, for example, Armstrong (2005) and Rochet and Tirole (2005) for overviews of the theory of two-sided markets, and Evans, Hagiu and Schmalensee (2006) for the economics, history and business analysis of a number of software-related platforms.

${ }^{10}$ For example, Wright (2004a).
} 
the reader side; it just ensures that the newspaper has enough readers so as to make it interesting for advertisers to pay to put their ads in the newspaper. Similarly, a small software editor who distributes the reader for free and charges a high price for the writer cannot be suspected of predation on one side and abusive pricing on the other. Regardless of the extent of competition in the industry, such pricing structures make good business sense; they also tend to be socially desirable for the same reason that they make business sense: They allow the platform to get both sides on board.

The paper offers a roadmap to the current economic thinking about the topic. It is organized as follows. Section 2 describes the fundamental externalities inherent in payment systems. Section 3 studies merchant resistance to interchange fee increases and the associations' determination of this fee. Section 4 first explains what implications the externalities identified in Section 2 have for welfare analyses. It then discusses whether consumer surplus (whose maximization is at the core of much antitrust practice) or social welfare (which is the standard focus of economic analyses) is the proper benchmark for the study of market failures and regulation in the payment card industry. Section 5 offers a critique of the current regulatory approach, and concludes with a call for more novel and innovative thinking about how to reconcile regulators' concerns and the industry legitimate desire to perform its balancing act.

\section{What are the main externalities?}

Public policy interventions must be grounded in the analysis of some market failure, for example the existence of non-internalized externalities among industry participants. As was recognized long ago by Baxter (1983), card payment systems involve three parties (system, issuer, acquirer) offering a service jointly to two other parties (cardholder, merchant). Card acceptance (by the merchant) or card usage (by the cardholder) usually are not the object of a negotiation between these two parties: Because of explicit constraints set by the systems or of transaction costs, merchants most often do not set different retail prices for card and cash payments ("price coherence").

Externalities of cardholders on merchants: because a merchant does not send a price signal to cardholders encouraging or discouraging them to use their cards (depending on whether the merchant benefits or loses from a particular card transaction), cardholders need not take the "right decision" when pondering over the use of card versus cash. That is, they may not internalize the merchant's welfare.

It might seem at first sight that, because of the merchants' individual ability to turn down the card, there could never be too many card payments by cardholders. This reasoning however is incorrect as it misses the point that merchants accept cards not solely for the convenience benefits (fraud protection, accounting facilities, time savings at the counter relative to check payments, transaction enablement through credit and float) that they derive from card usage, but also because card acceptance makes their store more attractive to consumers. That is, merchants realize that card acceptance is part of their quality of service (QoS) package and accordingly internalize, at least in part, the cardholders' net benefit from being able to use their card. Put differently, merchants may be willing to accept cards even if doing so is a money-losing proposition from a narrow accounting viewpoint, that is when the merchant discount exceeds the convenience benefit they themselves derive from card usage. 
Merchants' decision of whether to accept the card depends on the average net benefit enjoyed by cardholders. ${ }^{11}$ This average benefit exceeds their net benefit of marginal card usages (those for which cardholders are indifferent between using the card and paying by cash or check), which is by definition ${ }^{12}$ equal to 0 . Yet, when judging whether there are too many or too few card transactions, a social planner must look at whether the marginal transactions are warranted from a social point of view. ${ }^{13}$ This argument suggests that "merchant resistance" to cards, based on the higher average cardholder net benefit, is too weak, and that transactions for which the cardholder's net benefit is smaller than the loss the merchant incurs from card usage (recall that this loss can be as high as the cardholders' average benefit if the merchant fully internalizes cardholder net surplus) may occur in payment systems. That is, the cardholder's lack of internalization of the merchant's loss (which itself is based on the merchant's internalization of cardholders' welfare!) may lead to inefficient card transactions.

From the point of view of incidence rather than pure efficiency, this is not the end of the story: Merchants are likely to pass the extra costs, if any, of card transactions through to consumers in general, that is to cardholders and cash payers altogether. Put differently, the externality in the end by and large runs from cardholders to cash payers, not to merchants.

Externalities of merchants on cardholders: Conversely, a merchant may exert a negative externality on cardholders by not accepting the card. Suppose, in contrast with the discussion above, that consumers are poorly informed of the merchants' card acceptance policy. Once in the shop, they are deprived of their net benefit if the merchant turns down the card, which will be the case now if the merchant discount exceeds the merchant's convenience benefit. Imperfect information is the essence of this particular market failure.

Multiple card systems create scope for a related externality of merchants on cardholders: Rather than turning down payment cards altogether, the merchant may turn down cards which he finds expensive and accept only the cards with the lowest merchant discounts; the merchant may be particularly tempted to do so if cardholders have cards from several systems in their pocket (they "multi-home"). To the extent that cards with the lowest merchant discount are also the least attractive ones for the consumer (they correspond to a lower interchange fee, thus to a higher issuer cost and ultimately to a smaller bonus or a higher price for the cardholder), this attempt at "steering" the consumer toward the use of cards with lower cardholder benefits or higher per-transaction cardholder fees exerts a negative externality on the consumer.

Another externality: Suppose that association members or intermediaries (acquirers, issuers) are able to charge a mark-up over their perceived marginal cost (they have market power, which, as usual, does not imply that they make supra-normal profits since these markups may cover large fixed costs of operations). Then, merchants, when turning down the card, and cardholders, when deciding to use cash or a check, do not internalize the

\footnotetext{
${ }^{11}$ The cardholder's net benefit is the difference between the convenience benefit derived by the consumer (relative to the alternative means of payment) and the per-transaction fee paid by the cardholder (the latter fee is often zero, or negative as in the case of frequent flyer miles or cash-back bonuses).

${ }^{12}$ Marginal card transactions are defined as the ones for which the cardholder is indifferent between paying by card and by an alternative means of payment. Thus by definition the net cardholder benefit is equal to 0 for the marginal card transaction.

${ }^{13}$ This is particularly clear when all merchants get the same benefit from card transactions. In this case, the social planner only has to determine if the benefit of the marginal transaction for the cardholder is below or above the "net social cost", that is marginal cost minus merchant benefit.
} 
increase in profit that the intermediaries would make under a card payment. Whether this neglect should be counted as an externality or equivalently whether members' markups should be included into the computation of social welfare (thus distinguishing it from consumer surplus, equal to cardholders' plus merchants' surplus) will be discussed later on.

This section has focused on potential externalities. Whether these externalities are internalized depends as usual on the prices that merchants and cardholders face, and thus on the interchange fee.

\section{Interchange fee determination}

\subsection{Merchant resistance}

Suppose that cardholders (the "buyers", $B$ ) and merchants (the "sellers", $S$ ) are charged per-transaction fees $p_{B}$ and $p_{S}$ by their issuer and acquirer, respectively. (These fees can be negative, as when cardholders receive cash-back bonuses.) $p_{S}$ is known as the "merchant discount". Let $b_{B}$ and $b_{S}$ denote, for a given transaction, the per transaction convenience benefits of a card payment (or, equivalently, the convenience cost of a payment through an alternative means of payment).

We assume for the moment that $b_{S}$ is the same for all transactions. By contrast, $b_{B}$ may be consumer-specific ${ }^{14}$ or transaction-specific ${ }^{15}$. We focus on the latter for expositional simplicity. The cardholder's convenience benefit may depend on the presence of cash in his pocket, on the prospect of subsequent purchases, on the distance to the nearest ATM machine, or on the need to use the float or credit facility. Suppose that the consumer learns the realization of $b_{B}$ only once he has decided to make a purchase.

In this simple environment, the (per-transaction) average cardholder surplus can be written as:

$$
v=v\left(p_{B}\right)=\mathrm{E}\left[b_{B}-p_{B} \mid b_{B} \geq p_{B}\right] .
$$

Note that the cardholder will use his card if and only if his convenience benefit exceeds the per-transaction fee that he is charged by his issuer, hence the conditional expectation.

A key factor underlying the concept of "must-take card"16 invoked to motivate recent policy interv0ention with regards to the interchange fee is the extent to which card acceptance makes the merchant more attractive to cardholders. Cardholders, such as repeat buyers, who are well-informed about the merchant's card acceptance policy, view card acceptance as an increase, by an amount $v$, in the merchant's quality of service; put differently, these consumers are willing to pay an extra $v$. By contrast, one-time patrons and more generally poorly informed consumers are no more likely to patronize the merchant if the latter takes the card.

Let $\alpha(0 \leq \alpha \leq 1)$ denote the percentage of "informed purchases", that is the fraction of cardholders who are aware of the store's card acceptance policy before deciding to patronize it. The parameter $\alpha$ measures the degree of merchant internalization of cardholder surplus.

\footnotetext{
${ }^{14}$ As in Rochet and Tirole (2002).

${ }^{15}$ As in Wright (2004b).

${ }^{16}$ Vickers (2005).
} 
It is in the merchant's interest to accept the card as long as the sum of merchant surplus, $b_{S}-p_{S}$, and internalized cardholder surplus, $\alpha v$, is positive ${ }^{17}$ :

$$
\left[b_{S}-p_{S}\right]+\alpha v \geq 0 \text {. }
$$

In particular, whenever

$$
b_{S}<p_{S} \leq b_{S}+\alpha v,
$$

the merchant accepts the card even though card acceptance is a money-losing proposition from a narrow accounting viewpoint $\left(b_{S}<p_{S}\right)$.

From the merchant's viewpoint, card acceptance is one of many decisions that affect the store's attractiveness. For example, hiring more cashiers or offering convenient parking imply a direct loss for the merchant, but increase the quality of service (especially to timeconscious consumers) and attracts more shoppers to the store.

\subsection{Do merchants suffer an injury? And why do they oppose high interchange fees?}

In the absence of internalization of cardholder surplus by the merchants, payment card systems cannot charge a merchant discount exceeding the merchant's benefit, and so

$$
p_{S} \leq b_{S} .
$$

Consequently, card acceptance lowers merchants' cost of operating and thereby the retail price. As internalization increases and provided that the association induces a merchant discount in excess of $b_{S}$ (Section 3.4 will investigate whether this is indeed in the association's interest to do so), card acceptance raises retail cost and thereby the retail price.

Merchants are likely to pass through cost increases into the retail price. ${ }^{18}$ This implies that merchants in fact incur no injury. ${ }^{19}$ Rather, cross subsidies run from cash buyers, who pay a higher retail price and get no benefit from card payments, to card users, who benefit from a higher QoS but pay for only part of the cost of this increase in quality (note that we employ "card user" rather than "cardholders", since the latter are both "card users" and "cash buyers", depending on the transaction).

This observation raises the question of why courts award (or would award) large damages to merchants (who received $\$ 3$ billion in the Wal-Mart settlement) in the absence of evidence of actual retail profit loss. The standard response for why the damage awards need not reflect lost profits $^{20}$ is that the direct-purchaser rule acts as a deterrence mechanism by giving an incentive to the presumably best-informed parties to sue.

It also raises the question of why merchants across the world are the most vocal interest groups in attacking interchange fees. Besides the obvious fact that they are better

\footnotetext{
${ }^{17}$ Strictly speaking, this assertion requires either that $\alpha=0$ or 1 , or that retail demand is linear (so that informed and uninformed consumers' demands can be easily aggregated). But the gist of the analysis carries over more general demand functions.

${ }^{18}$ Whether the merchant engages in cost pass-through ( 1 for 1 increase), cost amplification (more than 1 for 1 ) or cost absorption (less than 1 for 1) in general depends on the exact shape of the demand functions faced by retailers. In the absence of detailed information, the assumption of a cost pass-through (which holds for example in the Hotelling model of product differentiation) is probably a reasonable first pass.

${ }^{19}$ On this, see also Farrell (2006).

${ }^{20}$ Dating back to at least Hanover Shoe, Inc. v. United Shoe Machinery Corp., (1968), and Illinois Brick Co v. Illinois, 431 U.S. 720 (1977) ( Supreme Court decision barring indirect purchasers from seeking damages in federal court).
} 
organized than, say, the group of cash buyers, there are several hypotheses in this respect. First, and consistent with the previous observation, they use the direct-purchaser rule to appropriate cash awards that (if interchange fees are indeed excessive) would go to cash buyers in a world of costless antitrust enforcement (which accordingly would award damages to parties that suffer the injury). Second, it may be the case that merchants actually suffer some injury, even though the latter is likely to be much smaller than the "excess interchange fees" that they end up paying. Conversely, they may increase their profit when the interchange fee is reduced. ${ }^{21}$ Third and a departure from the homogenousmerchants assumption, merchants may differ in the internalization parameter or in the convenience benefit that they derive from card transactions. Card payment systems, whether proprietary or not-for-profit, to some extent try to account for this heterogeneity and offer lower interchange fees/merchant discounts to certain classes of merchants. Such price discrimination however is necessarily limited. Merchants with more limited convenience benefits from cards have a relative preference for lower interchange fees (a lower volume of card transactions) compared to those with higher convenience benefits. The former may therefore object to an interchange fee policy that in part reflects the average merchant's concerns.

\subsection{How important are redistributive concerns?}

Keeping with the premise that $b_{S}<p_{S}$ and merchants still accept the card (card payments hence raise merchant cost and retail price), it is often argued in the policy debate that the subsidy flowing from cash payers to card users raises an equity concern, as the latter are usually wealthier than the former. Needless to say, equity concerns should be high on the policy agenda, although it is by no means clear that distorting competition policy is the most efficient way to redistribute from the rich to the poor. ${ }^{22}$ In the case of card payment systems, there are other reasons why redistributive concerns may not be central to the interchange fee debate:

- "Cash buyers" include, as we noted, cardholders who elect to pay by cash. The "subsidy" then flows between two different "incarnations" of the same person. ${ }^{23}$

- The truly destitute sometimes patronize hard discount shops that precisely do not take cards.

- Returning to the cashiers' analogy, supermarkets that hire sufficient staff or spend large amounts of money to develop electronic checkouts in order to keep queuing

\footnotetext{
${ }^{21}$ In particular, merchants may lobby for lower interchange if (perhaps due to consumer imperfect price information) prices are downward rigid in the short to medium run. Chang, Evans and Swartz (2005) find that merchants did little pass-through of lower interchange fees to consumers when the Reserve Bank of Australia mandated a decrease in interchange fees from around 0.95 percent of transaction value to 0.55 percent.

${ }^{22}$ Expressed in its extreme form, the Atkinson-Stiglitz theorem states that redistributions of arbitrary degrees should be entirely performed through the income tax, and should therefore be of no concern for other public policies. While this result hinges on strong assumptions, it serves as a reminder to those who would like to invoke redistributive concerns in order to tinker with sectoral policies. Indeed, competition policy often leaves redistributive concerns aside.

${ }^{23}$ When every consumer has a card, there may still exist redistributive concerns as different consumers may use cards in different amounts; it would then seem that redistributive concerns are of second order, but some empirical validation of this would be useful.
} 
time reasonable de facto subsidize time-conscious patrons to the detriment of less time-conscious ones. Yet the former are on average wealthier than the latter. More generally, cross-subsidies from the poor to the rich are often intermediated through store choices.

\subsection{Systems' choice of interchange fee}

Finally, let us turn to an association's choice of interchange fee. An implicit assumption in much of the policy debate is that high interchange fees are associated with issuer control of the association. Let us therefore posit that the interchange fee is selected in the issuers' best interest. Of the several determinants of equilibrium interchange fees, we emphasize two:

Merchants' internalization: We keep assuming merchant homogeneity and start with the case of a monopoly system. Under reasonable assumptions, the issuers' interest lies in maximizing the volume of card transactions, or equivalently in minimizing their own cost (maximizing the interchange fee) subject to the constraint that the merchants keep accepting the card. ${ }^{24}$ Thus, they select the interchange fee that makes merchants indifferent between accepting and refusing the card:

$$
p_{S}=b_{S}+\alpha v\left(p_{B}\right) .
$$

Letting $c$ denote the sum of the issuers' marginal cost, $c_{B}$, and the acquirers' marginal cost, $c_{S}$, and $m$ denote the sum of the issuers' and acquirers' markups ${ }^{25}$ ( $m_{B}$ and $m_{S}$, respectively), the not-for-profit property further yields:

$$
p_{B}+p_{S}=c+m \text {. }
$$

If acquirers are perfectly competitive, the equilibrium interchange fee $a$ that induces this merchant discount is given by:

$$
p_{S}=a+c_{S} .
$$

The exact same outcome prevails under perfect system competition as long as cardholders hold a single card (they "single-home"). Intuitively, under single-homing, each system holds a monopoly of access to its own cardholders (in the same way each telecom operator enjoys a monopoly over the termination of calls made to its subscribers). Thanks to this competitive bottleneck, it can "charge" a monopoly merchant discount. Cardholders are in the driver's seat, as systems try to woo them; however, competition for enlisting customers in this extreme case does not alter the allocation, since the monopoly system previously studied was assumed to be not-for-profit and therefore unable to raise price to cardholders.

Cardholder multi-homing: By contrast merchants are in the driver's seat when cardholders hold cards from multiple systems. Suppose for the sake of the argument that there are two competing card systems and that cardholders have a card on each of these systems. ${ }^{26}$ Merchants can then turn down the card with the higher merchant discount, knowing that cardholders will have the other card in their pocket. Of course, cardholders,

\footnotetext{
${ }^{24}$ The issuers' profit is equal to their margin times the volume of card payments. If the issuers' margin itself varies with the interchange fee (which depends on the nature of competition among issuers), then to the extent that the margin is decreasing in issuer marginal cost, issuers want to maximize the interchange fee for a second reason.

${ }^{25}$ These markups can be sizeable if fixed costs are large in the issuing or acquiring industries.

${ }^{26}$ In general the extent of multi-homing is endogenous (see for example Rochet and Tirole, 2003).

Considering the case of full multi-homing is only a short cut in order to simplify the exposition.
} 
for whom the former card is more attractive (it carries a higher interchange fee), may object to this strategy, and so the systems' incentive to "steer" (lower the merchant discount so as to induce merchants to abandon the rival card) depends on the extent of merchant internalization of cardholder surplus. Competing systems can be shown to leave merchants with a strictly positive surplus despite their homogeneity (see Rochet and Tirole, 2006):

$$
p_{S}<b_{S} .
$$

How much a surplus is left to merchants hinges on two considerations: First, they derive more surplus, the lower their degree of cardholder surplus internalization. As in the case of single-homing, merchant internalization of cardholder surplus tends to raise the equilibrium merchant discount. Second, and less obviously, a system may reduce its interchange fee so as to raise the issuers' cost and to thereby put downward pressure on their markup if the latter indeed decreases with issuer cost.

\section{$4 \quad$ Welfare analysis}

\subsection{Fixed industry structure}

Let us for the moment take as our benchmark the standard economic notion of social welfare, equal to the sum of all surpluses in the economy:

$$
\begin{gathered}
\text { Social welfare }=\text { card users' }+ \text { cash buyers' }+ \text { merchants' }+ \text { association } \\
\text { members' surpluses }
\end{gathered}
$$

We first adopt a short-term view by taking the industry structure (merchants, issuers, acquirers) as given. That is, we ignore entry and exit. Given merchant homogeneity and assuming that the merchants pass-through the interchange fees into their retail price, social welfare is maximized when a) merchants accept the card, and b) cardholders make proper use of their card, in the sense that they use the card if and only if the social benefit exceeds the social cost, or:

$$
b_{B}+b_{S} \geq c .
$$

Because cardholders use their card whenever:

$$
b_{B} \geq p_{B},
$$

the cardholder fee must be equal to cost minus the merchant's convenience benefit:

$$
p_{B}=c-b_{S} \text {. }
$$

But

$$
p_{B}+p_{S}=c+m
$$

(where, recall, $m$ is the sum of issuer and acquirer markups: $\mathrm{m}=m_{B}+m_{S}$ ). Hence social efficiency requires that merchants pay the sum of their convenience benefit and the intermediaries' markup:

$$
p_{S}=b_{S}+m .
$$


Intuitively, this markup inefficiently reduces card demand, and merchants are asked to offset it in order to provide cardholders with the proper incentive to use their card.

Recall, though, that merchants turn down the card whenever:

$$
p_{S}>b_{S}+\alpha v \text {. }
$$

Hence there are two cases: if $m<\alpha v$. then the first best is attainable and the socially optimal merchant discount is $p_{S}=b_{S}+m$. If by contrast $m>\alpha v$, the first best is not attainable and the second best socially optimal merchant discount is the maximum value that merchants are ready to accept, namely $p_{S=} b_{S}+\alpha v$.

Applying the analysis of Section 3.4, we can now compare the welfare optimum and the issuers' choice.

Single-homing: Recall that when cardholders have only one card, the association chooses the highest interchange fee/merchant discount that is consistent with merchant acceptance:

$$
p_{S}=b_{S}+\alpha v \text {. }
$$

Hence if

$$
\alpha v>m,
$$

the interchange fee chosen by the association is socially too high. By contrast, if

$$
\alpha v \leq m \text {, }
$$

it is (constrained) optimal in the sense that a social planner would choose the same interchange fee as the association.

Multi-homing: When cardholders have multiple cards, we saw that the associations' ability to steer leads to merchant discount:

$$
p_{S}<b_{S}
$$

The interchange fee is then socially too small.

\subsection{Consumer surplus or social welfare?}

Leading economists have questioned issuers' and acquirers' profits should not be accounted for in social welfare:

"For ensuring that customer-merchant pairs choose the best deal for them, it doesn't matter whether a deal is less good because "real" processing costs are high or because of markups, nor, if the latter, whether the quasi-rents are dissipated or not. The key is simply letting two-sided customers pick the best deal. If one wants to evaluate efficiency rather than competitiveness (or consumer welfare), obviously it does matter. Certainly in the US credit card issuers spend lots of resources on marketing. Would it be much less with a fee structure (lower interchange than today) that made merchants indifferent?” (Farrell 2006)

"..the argument that the interchange fee should be raised in order to subsidize imperfectly competitive issuers is unappealing. First, in so far as there is imperfect competition, it should be addressed by pro-competitive measures, not rewarded by subsidy. (Pushed to an extreme, the argument would favor subsidizing cartels.) Second, any subsidy has to be financed by, effectively, a tax on retail purchases. It may be that some of the tax implied by a high interchange fee is recycled to card-paying consumers (for instance, via the interest-free period and rewards for card use), but the recycling may well be imperfect and inefficient. Moreover, there is usually no interest-free period for the many payers by credit card who do not routinely clear their balances in full, and in the absence of frictionless surcharging, those paying other than by credit card get no tax rebate at all. So besides the general unattractiveness of subsidizing imperfectly competitive firms, the effective tax to finance the subsidy would seem likely itself to be inefficient and distorting. " (Vickers 2005) 
We offer two ways of looking at this (complex) issue.

Consumer surplus maximization: Let us take association members' profit out of the social welfare function. Given that merchants pass cost increases through to consumers, this leaves us with:

Consumer surplus $=$ cash users' + cardholders' + merchants' surplus.

Viewed from end-users' standpoint, the total cost of card transactions is $c+m$ : As Farrell notes in the citation above, it does not matter whether the processing costs are high or whether intermediaries levy markups. Consumer surplus optimization requires that the card be used if and only if end-users' combined benefit exceeds their perceived total cost:

$$
b_{B}+b_{S} \geq c+m \text {. }
$$

Going through the same steps as earlier, the consumer-surplus-maximizing merchant discount is just the merchant convenience benefit:

$$
p_{S}=b_{S} \text {. }
$$

Thus, from the point of view of consumer surplus, the interchange fee is unambiguously too high under cardholder single-homing and too low under multi-homing.

Should markups be part of social welfare? To simplify the exposition, we will assume that only issuers have market power (in the formulae above only the total markup $m$ mattered. We assume that $\left.m=m_{B}\right)$. As we earlier discussed, inflating the interchange fee to offset the market power distortion $m$ reflects the desire to subsidize the cardholders' usage and provide them with the correct "price signal". However, this subsidization also inflates issuers' profit in two ways: first by increasing the volume of card usage and thereby, and mechanistically, issuer profit, and second, in situations where the issuer markup decreases with their marginal cost, by augmenting this markup.

Consider two polar views of the issuing industry:

- Cozy cartel: In this first view, issuers' markup stems from tacit collusion among large issuers protected from effective entry by barriers to entry. ${ }^{27}$ Furthermore, the resulting supra-normal profits are either dissipated through an "easy life" and inefficient production of card services, or go to wealthy shareholders whose marginal utility of income is much lower than that of the average consumer. Then issuers' markup should not be counted as part of social welfare.

One may however wonder whether antitrust authorities that would be using this argument (in the case of single-homing in our analysis) to justify regulating down the interchange fee would be focusing on the right locus of intervention. As pointed out by Vickers (2005), a more efficient public policy might be to confront industry cartelization directly rather than to tinker with the interchange fee.

Perhaps more complex is the case of wasteful competition. Suppose that issuers do not tacitly collude, but compete in ways that bring limited benefits to consumers. ${ }^{28}$ Then, if one cannot directly confront the source of wasteful competition, indeed it seems reasonable not to account for issuer profits.

\footnotetext{
27 These barriers would be unrelated to an inability of new entrants to have access to associations, which by and large are open.

${ }^{28}$ The large advertising expenditures mentioned by Farrell in the above citation sometimes fall into this category, while introductory price concessions or innovative offerings do not.
} 
- Monopolistic competition (large fixed costs and free entry into issuing): The opposite polar stance views the issuing industry as one with non-negligible market power but no supra-normal profits and in which entry is limited by the presence of large fixed costs. ${ }^{29}$ According to this position (which is similar to the one taken in intellectual property law, which views markups as the necessary engine of product introduction and innovation), an increase in the issuers' short-term profit brought along by an increase in the interchange fee translates into more entry into issuing and results in either stronger price competition and lower markups or in increased product variety. The issuers' markup is then in the long term tantamount to consumer surplus. ${ }^{30}$ Indeed in a long-run equilibrium with free entry, there is no issuer profit and no distinction between consumer surplus and social welfare.

In summary, the question of whether social welfare or consumer surplus is the right benchmark requires considering the range of arguments just described.

\section{$5 \quad$ Assessing the current regulatory approach}

Despite recent progress, our understanding of theoretical and especially empirical aspects of the payment card industry is still incomplete. Hopefully research will shed further light on the relevant issues in the near future. Two points are worth making regarding the current regulatory approach, though.

Need for consensus building: It may be useful to compare the current regulation of payment card associations in several regions of the world and the regulation of local loop access in telecoms. In the case of telecoms a rather broad consensus emerged among economists that the local loop at the time was a natural monopoly and that the resulting lack of competition in telecom services led to high costs and high prices. [Of course, the consensus to some extent pre-dated the evolution of the past 25 years and a cost-based regulation was already in place. Another broad consensus held however that this regulation was inefficient and resulted in poor incentives and a rather distorted ("anti-Ramsey") price structure]. Second, innovative solutions, in the form of incentive regulation and price caps, were designed. Interestingly for our subject, the price-cap approach decentralizes the choice of relative prices to the regulated firm and reflects the philosophy that the major monopoly price ${ }^{31}$ distortion has to do with the price level, not the price structure. ${ }^{32}$

In the context of card payment systems, and given that a large majority of merchants take the card, the market distortion, if any, must come from an excessive number and usage of cards. ${ }^{33}$ In the absence of strong theoretical case and empirical evidence on deadweight losses, the debate still has too much of a flavor of "My gut feeling is that there are too

\footnotetext{
${ }^{29}$ These large fixed costs then are incurred only by large players; small banks whose only ambition is to issue plain vanilla cards for their depositors would not incur fixed costs of a similar magnitude.

${ }^{30}$ This discussion skips over the well-known question about whether there is too much or too little entry into issuing for a given cost structure. But in the absence of further information, the discussion seems a fine benchmark.

${ }^{31}$ The cost distortion is addressed through high-powered incentive schemes.

${ }^{32}$ Indeed, under some conditions the regulated firm subject to a price cap selects the same prices as the social planner would do. See for example Laffont and Tirole (1999). Decentralization through price caps may however be costly under certain forms of informational asymmetries (Armstrong and Vickers 2000).

${ }^{33}$ Or from an excessive use of high-cost payment systems to the detriment of lower-cost ones.
} 
many/ about the right amount of (depending of where one stands) card payments". This point is not intended as a criticism as "gut feelings" are as good as it comes in the absence of clear theoretical and empirical guidelines. Rather, we feel that it is incumbent upon economists to design simple theoretical tests of over-or under-usage and to bring the theory to the data.

Looking ahead: At this stage, the regulatory and court attention has by and large focused on cooperatives. While cooperatives may hurt competition and therefore should not be exempted from antitrust laws, it is unclear either why they should receive a special treatment: While their higher market share may raise concerns of dominance, such concerns play out in antitrust theory through the likely ability to raise price, an ability that not-for-profits do not possess.

As we discussed, the general issue raised by merchants and regulators is that of high merchant discounts, whether these are chosen (directly) by a proprietary system or (indirectly) by an association. To be certain, antitrust officials are sophisticated and see through the corporate veil, and so it is an easy guess that proprietary systems such as American Express and Discover are next in line in the regulatory agenda. ${ }^{34}$

Setting up a regulation requires having a vision as to what is likely to happen in the presence or absence of regulation. Such analysis is lacking and developing such scenarios lies way beyond the scope of this paper. Let us therefore content ourselves with stating a couple of relevant questions: i) If Visa's interchange fee is reduced by regulation, will issuers gradually move their business to alternative platforms (in particular, by switching new customers as well as existing ones at card renewal)? ii) Will large issuers such as Citigroup or Bank of America start their own proprietary systems (with or without integrating into acquiring)? iii) How will new payment platforms such as Pay Pal take advantage of the consumer demand for attractive payment systems if offers by incumbents (Visa, MasterCard, American Express, and Discover) are constrained by regulation? Should we expect merchant discount regulation to spread to the entire payment industry and how effective would such a regulation be? Existing regulations and their likely nearfuture variants are intrinsically asymmetric ones, and one should ponder over their likely impact on the future of the industry.

Finally, if we decide that regulation is warranted, we ought to devise, like for telecoms, innovative forms of regulation. The cost-based approach currently used in several countries is well-known to lack intellectual foundations and therefore to be rather arbitrary.

\footnotetext{
${ }^{34}$ An alternative hypothesis is that regulators hope that the proprietary systems' merchant discounts will move down in reaction to the mandated reduction in Visa and MasterCard's interchange fees.

It is interesting to contemplate whether, both theoretically and empirically, such a bandwagon effect is likely. From a theoretical viewpoint, the analysis of Section 3 shows that in the case in which interchange fees may be socially excessive (the case of cardholder single-homing), the unregulated systems' merchant discount is non-responsive to other systems' merchant discount. More precisely, they continue charging the sum of merchants' convenience benefit and internalized cardholder surplus whether they are proprietary of not-forprofit; proprietary systems may however change their cardholder fee (and therefore indirectly through this rule, the merchant discount) in response to the regulation of associations. Of course, we need to figure out empirically whether the case of single-homing or that of multi-homing is more descriptive (reality clearly lies somewhere in between); but for the purpose of this exercise, it makes a lot of sense to place ourselves under the conditions that may make associations' interchange fee too high socially. Thus we should expect little reaction of unregulated merchant discounts whenever regulation is warranted.

Empirically it will be interesting to see whether proprietary systems' merchant discount move in synchronicity with those of regulated systems. To date, the evidence in Australia rejects this hypothesis, but longer-term and cross-country evidence will inform us better on this question.
} 
We ought to think about new alleys that won't distort system competition and will provide flexibility to systems if regulation is actually heading the wrong way while assuaging the regulators' fears about socially excessive interchange fees.

\section{$6 \quad$ References}

Armstrong, M. (2005) "Competition in Two-sided Markets," forthcoming, Rand Journal of Economics.

Armstrong, M. and J. Vickers (2000) "Multi-product Price Regulation under Asymmetric Information,” Journal of Industrial Economics, 48: 137-160.

Chang, H., D. Evans, and G. Swartz (2005) "The Effect of Regulatory Intervention in Two-Sided Markets: An Assessment of Interchange-Fee Capping in Australia," Review of Network Economics, 4: 328-358.

Evans, D., A. Hagiu, and R. Schmalensee (2006) Invisible Engines. MIT Press: Cambridge.

Farrell, J. (2006) "Efficiency and Competition between Payment Instruments," Review of Network Economics, 5: 26-44.

Rochet, J.C., and J. Tirole (2002) "Cooperation among Competitors: The Economics of Payment Card Associations," Rand Journal of Economics, 33: 1-22.

Rochet, J.C., and J. Tirole (2003) "Platform Competition in Two-Sided Markets," Journal of the European Economic Association, 1: 990-1029.

Rochet, J.C., and J. Tirole (2005) "Two-Sided Markets: A Progress Report," Rand Journal of Economics, forthcoming.

Rochet, J.C., and J. Tirole (2006) "Must-Take Cards: The Welfare Impact of Interchange Fees," mimeo, IDEI.

Vickers, J. (2005) "Public Policy and the Invisible Price: Competition Law, Regulation and the Interchange Fee", Proceedings of a Conference on "Interchange Fees in Credit and Debit Card Industries", Federal Reserve Bank of Kansas-City, Santa Fe, New Mexico, May 4-6, 231-247.

Wright, J. (2004a) "One-Sided Logic in Two-Sided Markets", Review of Network Economics, 3: 42-63.

Wright, J. (2004b) "The Determinants of Optimal Interchange Fees in Payment Systems," Journal of Industrial Economics, 52: 1-26. 